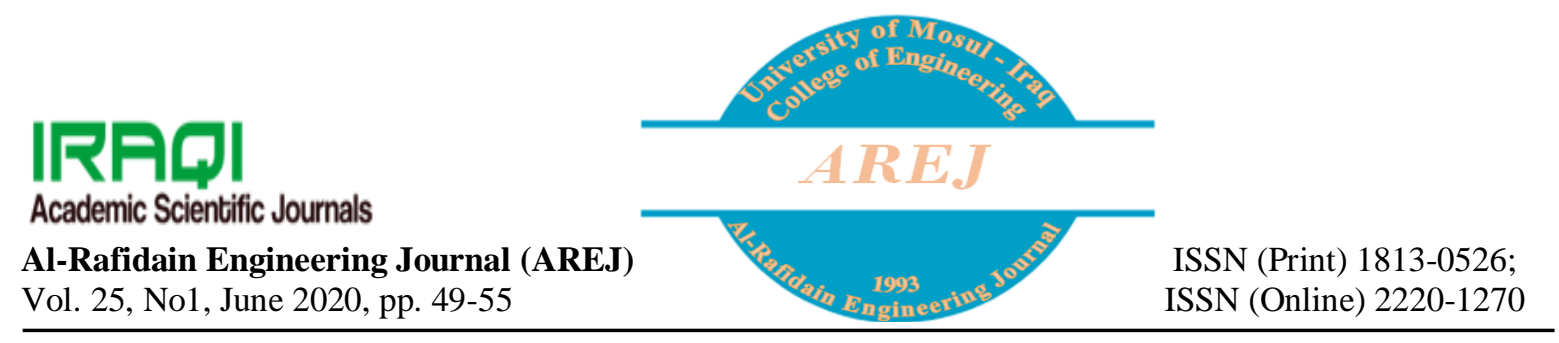

\title{
A Comparison Study of the Most Important Types of the Flexible Alternating Current Transmission Systems (FACTs)
}

\author{
Ahmed N. Alsammak \\ ahmed_alsammak@uomosul.edu.iq
}

\author{
Hasan A. Mohammed
}

hasan82adnan@uomosul.edu.iq

Electrical Engineering Department, Collage of Engineering, University of Mosul

Received: 29/3/2020

Accepted: $16 / 5 / 2020$

\begin{abstract}
The Flexible Alternating Current Transmission systems(FACTs) devices is power electronics constructed system used to increase the capability of the transmission line. It has several types with different functions for example: SVC, STATCOM,DSTATCOM, TCSC, SSSC, IPFC and UPFC. The Static Synchronous Series Compensator (SSSC) used to control the active power of the transmission line by injecting controllable ac voltage in the series with the transmission line. The Static Synchronous Compensator (STATCOM) employed to control the reactive power by injecting adjustable ac current in the transmission line. The Unified Power Flow Controller (UPFC) consists of SSSC and STATCOM linked by DC capacitor, it controls both active and reactive power flow of the line. This paper presents a simulation study to compare between SSSC, STATCOM and UPFC by inserting each device separately on a 100 MVA, $500 \mathrm{KV}$, four busses power system. Each converter is designed by 48-pulse multilevel inverter to reduce harmonics contents of the line voltage. This study has been done using MATLAB / SIMULINK package.
\end{abstract}

Keywords:

FACTs, SSSC, STATCOM, UPFC, Voltage Stability, and Power Flow.

https://rengj.mosuljournals.com

Email: alrafidain_engjournal1@uomosul.edu.iq

\section{INTRODUCTION}

Recently, the use of electrical power has increased widely while the growing of power generation and transmission has been strictly limited because of limited resources and environmental limitations. Transient stability acts an important issue in holding the system stability under huge disturbances and faults situations. The Flexible Alternating Current transmission systems (FACTs) devices plays an important role to mitigate different types of power scheme problems, it have the capability to control the active and reactive power flows in a transmission line by regulating its series and shunt parameters, and it has ability to enhance the performance of poor ac systems and increasing transmission capabilities over long ac lines.

The FACTs devices could enhance the performance of the system and improve power flow through transmission lines [1]. In addition to above these devices are used to improve the steady state and transient stability, controlling dynamic response, enhancing voltage stability and controlling impedance and phase angle of the transmission line [2].

There are different varieties of FACTs devices such as TCSC, SSSC, SVC, STATCOM, STATCOM, UPFC, IPFC etc. [3]. The SSSC is one of FACTS devise that injects a controllable ac voltage in series with the transmission line [4], it is used to control the active power of the transmission line [5].

The STATCOM is a solid state voltage source inverter connected in shunt with the transmission line through coupling transformer. It is used to regulate line voltage by compensating the required reactive power $(\mathrm{Q})[6]$.

The UPFC is one of the FACTs devices with multipurpose usages that is used to adjust 
line parameters simultaneously [7]. It is consist of series and shunt converters linked through DC capacitor. The series converter operates as SSSC controller, whereas the shunt converter represent a STATCOM, so the UPFC has the ability to control both active and reactive power flow of the system [8].

\section{THE FLEXIBLE ALTERNATING CURRENT TRANSMISSION SYSTEMS FACTS CONTROLLERS}

The FACTs controllers may be use gate turn-Off thyristor (GTO) or insulated gate bipolar transistor (IGBT). The main advantages of the FACTs controllers are compensating needed reactive power, regulating line voltage, controlling an active and reactive powers, balancing line voltage, damping the oscillations, enhancing steady state and transient stability etc.

\section{STATIC SYNCHRONOUS \\ COMPENSATORS (STATCOM)}

The Static Synchronous Compensators (STATCOM) is shunt connected voltage source inverter can be used to control the ac system voltage by injecting a capacitive or inductive current. The difference between ac output voltage of the STATCOM ( $\left.\mathrm{V}_{\text {statcom }}\right)$ converter and system voltage $\left(\mathrm{V}_{\text {system }}\right)$ controls the main function of the STATCOM, where if $\left(\mathrm{V}_{\text {system }}>\mathrm{V}_{\text {statcom }}\right)$ the STATCOM will operates as inductive load absorbs reactive power (Q), while if $\left(\mathrm{V}_{\text {system }}<\mathrm{V}_{\text {statcom }}\right)$ the STATCOM will operates as capacitive load injects reactive power $(\mathrm{Q})$ to the system [9]. The STATCOM has several advantages like increasing the capability of the transmission line, providing (or absorbing) the needed reactive power in a sufficient and rapidly way and regulating line voltage decreasing the power losses [10]. Fig. 1 shows the schematic diagram of STATCOM and its characteristic.

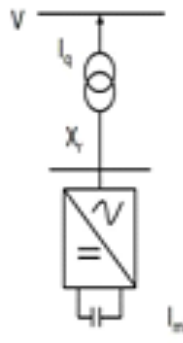

(a)

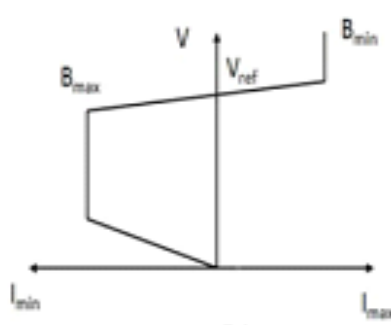

(b)
Fig. 1 STATCOM configuration, where:

(a) Schematic diagram, (b) Characteristics.

\section{STATIC SYNCHRONOUS SERIES COMPENSATORS (SSSC)}

Compensator (SSSC) is a series connected voltage source inverter, which is connected in series with the transmission line through series transformer. The SSSC injects series voltage, this voltage is nearly vertical with line current. The SSSC will be seen as a controllable impedance(inductive or capacitive) load depending on the direction of current that lead to control active power flow through the transmission line[11]. The SSSC used to control active power of the transmission line by injecting (or absorbing) controllable voltage in series with the transmission line [12]. Fig. 2 shows the schematic diagram and characteristics of SSSC.

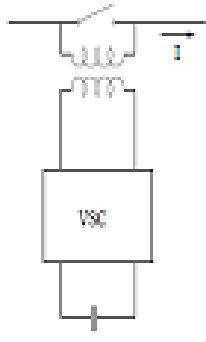

(a)

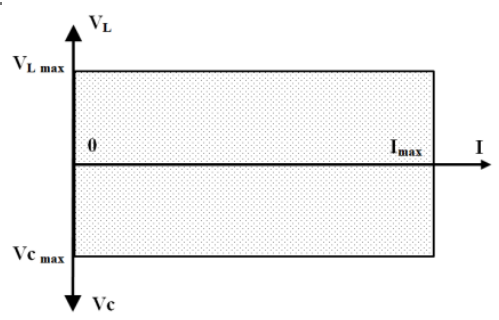

(b)
Fig. 2 SSSC configuration.

(a) Schematic diagram, (b) Characteristics.

\section{UNIFIED POWER FLOW CONTROLLER (UPFC)}

The UPFC is a multifunction device that consists of series and shunt converters. The series converter operates as SSSC controller used to inject a controllable series voltage and controls the active power flow through the transmission line. The shunt converter works as STATCOM used to control the reactive power at the common point and provides (or absorb) the active power needed by the series converter, so the UPFC use to control both active and reactive power flow of the transmission lines. It can control all line parameters (voltage, impedance and load angle) thus it called unified [13]. In addition to above the UPFC used to enhance the stability, mitigates the power oscillations that caused due to wind energy or fault occurring and this device used to limiting the short circuit current [14].The circuit diagram of a UPFC is shown in Fig. 3. 


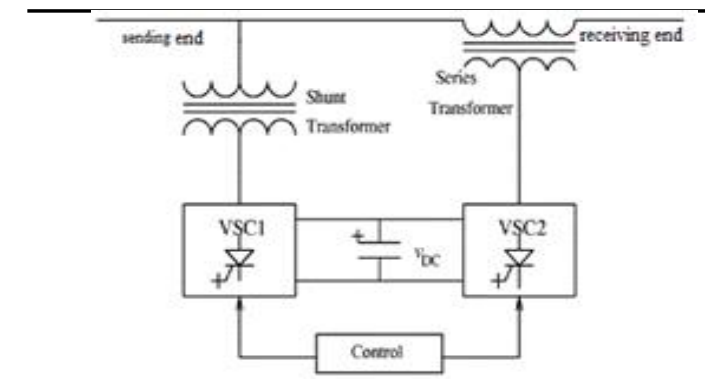

Fig. 3 The schematic diagram of UPFC.

\section{MATHEMATICAL ANALYSIS F 48- \\ PULSE VOLTAGE SOURCE \\ CONVERTER}

The 48-pulse Multilevel Inverter (MLI) consists of four of three-level 12-pulse inverters. Each inverter is modeled by 12 switch distributed onto three legs and each leg contains four switches. The two lower switches are operated in complementary of the two upper switches. The DC link of the inverters are connected in parallel way and connected to the DC capacitor, while the ac side are connected in series way that lead to obtain an output voltage of 48 pulse injected to the grid through four zigzag transformers $\left(T_{1}, T_{2}\right.$, $\left.\mathrm{T}_{3}, \mathrm{~T}_{4}\right)$.

The phase shift formed by the primary windings of $T_{1}$ and $T_{2}$ is $+7.5^{\circ}$ as well as the phase shift formed by the other transformers $\mathrm{T}_{3}$ and $\mathrm{T}_{4}$ is $-7.5^{\circ}$, while the phase shift formed by the delta (D) secondary windings of $\mathrm{T}_{2}$ and $\mathrm{T}_{4}$ is $-30^{\circ}$, if the $T_{1}$ is taken as a reference then the phase shift of the transformers will be $(0,-30,-15$ and -45$)$ respectively.

The $30^{\circ}$ phase shift that produced by delta connections (D) and star connection (Y) cancels harmonics orders of $(5+12 n)$ and $(7+12 n)$, while the $15^{\circ}$ phase shift between the first group $\left(\mathrm{Y}_{1}, \mathrm{D}_{1}\right)$ and the second group $\left(\mathrm{Y}_{2}, \mathrm{D}_{2}\right)$ cancels harmonics orders of $(11+24 n)$ and $(13+24 n)$, so the line voltage of the 48-pulse MLI is nearly sinusoidal waveform.

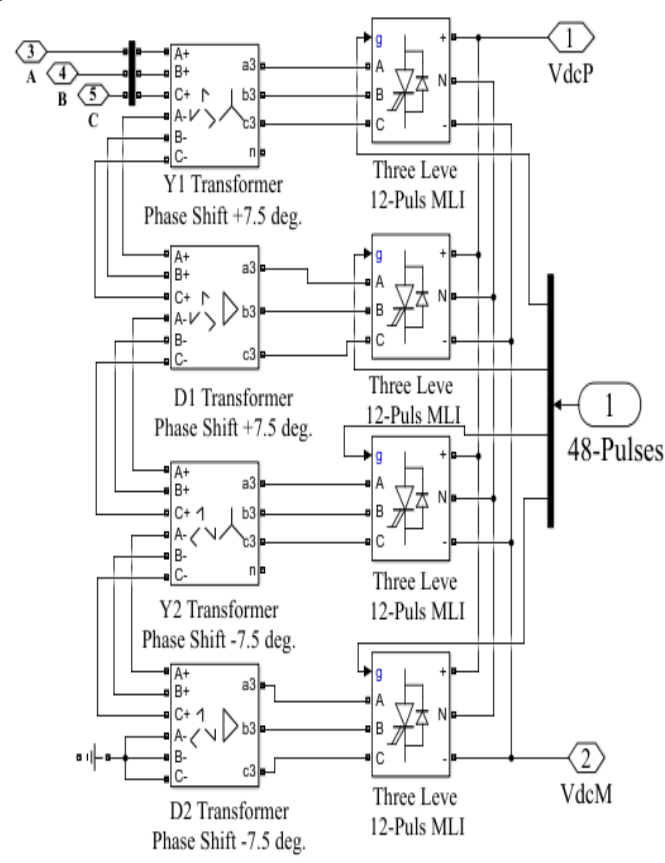

Fig. 4 48-Pulse of a three-level four-cascaded MLIs.

The resultant output voltage generated by the first 12-pulse converter is expressed by equation (1).

$$
\begin{aligned}
V_{a b 12}(t) 1=2\left[V_{a b 1}\right. & \sin \sin \left(w t+30^{\circ}\right)+V_{a b 11} \\
& \sin \sin \left(11 w t+195^{\circ}\right) \\
& +V_{a b 13} \\
& \sin \sin \left(13 w t+225^{\circ}\right) \\
& +V_{a b 23} \sin \sin \left(23 w t+60^{\circ}\right) \\
& +V_{a b 25} \sin \sin \left(25 w t+120^{\circ}\right) \\
& +\cdots]
\end{aligned}
$$

The resultant output voltage generated by the second 12-pulse converter is expressed by equation (2).

$$
\begin{aligned}
& V_{a b 12}(t) 2 \\
& =2\left[V_{a b 1} \sin \sin \left(w t+30^{\circ}\right)+V_{a b 11}\right. \\
& \sin \sin \left(11 w t+15^{\circ}\right)+V_{a b 13} \\
& \sin \sin \left(13 w t+75^{\circ}\right)+V_{a b 23} \\
& \sin \sin \left(23 w t+60^{\circ}\right)+V_{a b 25} \\
& \sin \sin \left(25 w t+120^{\circ}\right) \\
& +\cdots]
\end{aligned}
$$

The resultant output voltage generated by the third 12-pulse converter is expressed by equation (3).

$$
\begin{aligned}
& V_{a b 12}(t) 3 \\
& =2\left[V_{a b 1} \sin \sin \left(w t+30^{\circ}\right)+V_{a b 11}\right. \\
& \sin \sin \left(11 w t+285^{\circ}\right)+V_{a b 13} \\
& \sin \sin \left(13 w t+345^{\circ}\right)+V_{a b 23} \\
& \sin \sin \left(23 w t+240^{\circ}\right)+V_{a b 25} \\
& \sin \sin \left(25 w t+300^{\circ}\right) \\
& +\cdots]
\end{aligned}
$$

The resultant output voltage generated by the fourth 12-pulse converter is expressed by equation (4). 


$$
\begin{aligned}
& V_{a b 12}(t) 4 \\
& =2\left[V_{a b 1} \sin \sin \left(w t+30^{\circ}\right)+V_{a b 11}\right. \\
& \sin \sin \left(11 w t+105^{\circ}\right)+V_{a b 13} \\
& \sin \sin \left(13 w t+165^{\circ}\right)+V_{a b 23} \\
& \sin \sin \left(23 w t+240^{\circ}\right)+V_{a b 25} \\
& \sin \sin \left(25 w t+300^{\circ}\right) \\
& +\cdots]
\end{aligned}
$$

These four identical 12-pulse converters provide shifted ac output voltages, described by equations (1) to (4), are added in series on the secondary windings of the transformers. The net 48-pulse ac total output voltage is expressed by equation (5).

$$
\begin{gathered}
V_{a b 48}(t)=V_{a b 12}(t) 1+V_{a b 12}(t) 2+V_{a b 12}(t) 3 \\
+V_{a b 12}(t) 4(5)
\end{gathered}
$$

The net 48-pulse output voltage $v_{\mathrm{ab} 48}(\mathrm{t})$ is expressed by equation (6).

$$
\begin{aligned}
& v_{a b 48}(t) \\
& =8\left[V_{a b 1} \sin \sin \left(w t+30^{\circ}\right)+V_{a b 47}\right. \\
& \sin \sin \left(47 w t+150^{\circ}\right)+V_{a b 49} \\
& \sin \sin \left(49 w t+210^{\circ}\right)+V_{a b 95} \\
& \sin \sin \left(95 w t+330^{\circ}\right)+V_{a b 97} \\
& \sin \sin \left(97 w t+30^{\circ}\right) \\
& +\cdots]
\end{aligned}
$$

The magnitudes of $\mathrm{V}_{\mathrm{bc} 48}(\mathrm{t})$ and $\mathrm{V}_{\mathrm{ca} 48}(\mathrm{t})$ are same $\mathrm{V}_{\text {ab48 }}(\mathrm{t})$ then shifted by $120^{\circ}$ and $240^{\circ}$ respectively [15].

\section{THE SIMULATION RESULTS}

The proposed system consists of a 100MVA, $500 \mathrm{kV}$, four buses, three transmission lines $\left(\mathrm{L}_{1}=200 \mathrm{Km}, \mathrm{L}_{2}=75 \mathrm{Km}, \mathrm{L}_{3}=180 \mathrm{Km}\right)$ and two of 100 MVA, 48-Pulse converters. Both converters are connected between the first and second buses at the second line $\left(\mathrm{L}_{2}=75 \mathrm{Km}\right)$ as shown in Fig. 5. The shunt converter represented as a STATCOM and is connected with the grid at the lift side of the second line $\left(\mathrm{L}_{2}=75 \mathrm{Km}\right)$ through shunt transformer, while The series converter represented as a SSSC connected with the grid at the right side of the same line. There is a selector switch between the two converters that allows to select the required operating mode between STATCOM, SSSC and UPFC Controllers.

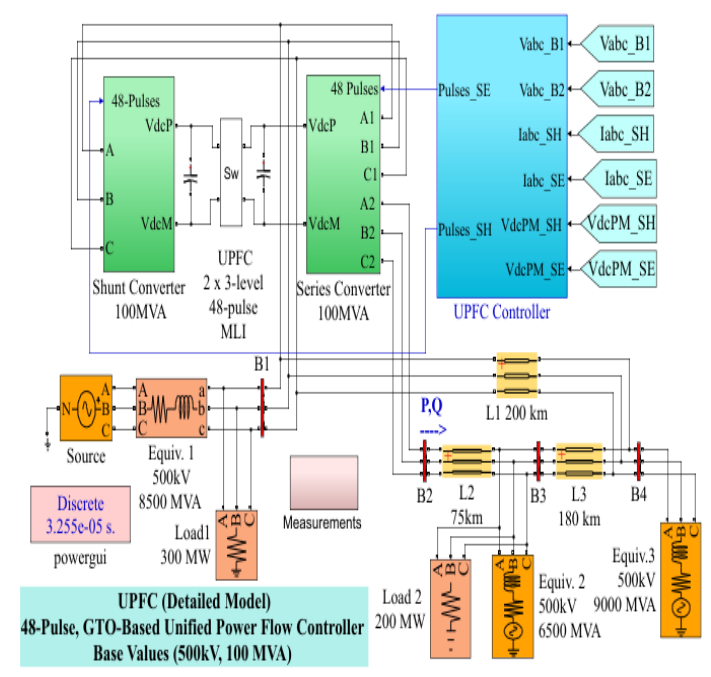

Fig.5 The simulink block diagram of the system.

The STATCOM is connected with $\left(\mathrm{L}_{2}=75 \mathrm{Km}\right)$ through shunt transformer used to compensate the reactive power $(\mathrm{Q})$ and regulate voltage of the second line. The series converter is operated as SSSC, it is connected in series with the second line $\left(\mathrm{L}_{2}=75 \mathrm{Km}\right)$ through series transformer, the main function of this converter is controlling the active power $(\mathrm{P})$ of the transmission line by injecting $10 \%$ of the rated voltage $(50 \mathrm{kV})$ in series with $\mathrm{L}_{2}$. So as to control active and reactive power flow of $\mathrm{L}_{2}$, both converters should be coupled by the selector switch and operated simultaneously as a UPFC mode.

\subsection{STATCOM Mode}

The main objective of the STSTCOM is compensate the reactive power $(\mathrm{Q})$ transmitted by the transmission line. Initially the reactive power of the system is zero and it increased to $(\mathrm{Q}=+0.7$ p.u) at 0.4 second, then at 0.5 second the reactive power decreased to be $(\mathrm{Q}=-0.7$ p.u $)$ so the FACTs controller device (STATCOM) used to control the reactive power of the second line as clear in Fig. 6.

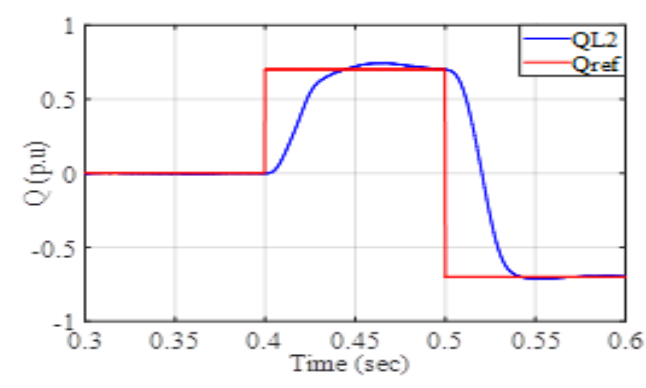

Fig.6 Reactive power (Q) of $\mathrm{L}_{2} \mathrm{vs}$ Time (STATCOM mode). 
The principle operation of the STATCOM can be explain briefly through Fig. 7, during the first region that limited between starting to $(\mathrm{T}=0.4 \mathrm{sec})$, the magnitude value of the system voltage $\left(\mathrm{V}_{\text {system }}\right)$ is equal to the magnitude of the STATCOM voltage $\left(\mathrm{V}_{\text {statcom}}\right)$, so the injecting current to the system is zero. For the period $(0.4 \leq \mathrm{T} \leq 0.5)$ seconds, the reactive power is positive value, the magnitude $\mathrm{V}_{\text {system }}$ is greater than $\mathrm{V}_{\text {statcom }}$ thus the resultant current follows from the system to the STATCOM and lagging from $\mathrm{V}_{\text {statcom }}$ by $90^{\circ}$ so the system will sees the STSTCOM as inductive load. For the last region at time is greater than $(\mathrm{T}=0.5 \mathrm{sec})$ the reactive power is negative value, the magnitude $\mathrm{V}_{\text {system }}$ is less than $\mathrm{V}_{\text {statcom }}$ thus the resultant current follows from the STATCOM to the system and leading $\mathrm{V}_{\text {statcom }}$ by $90^{\circ}$ so the system will sees the STATCOM as capacitive load.

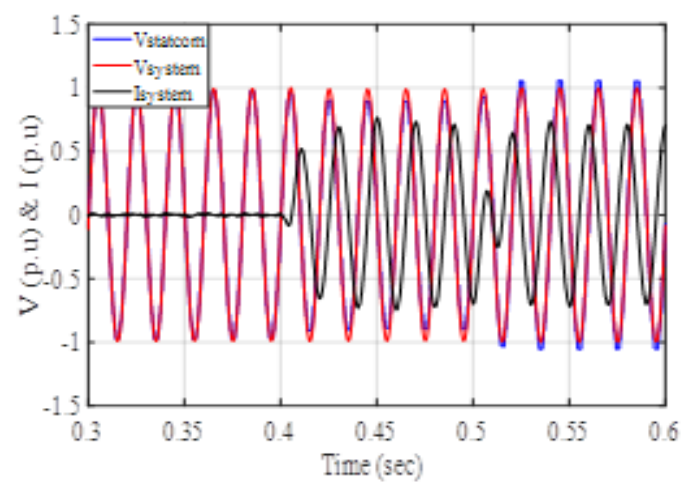

Fig. 7 Voltages and current (STATCOM mode).

The DC capacitor voltage $\left(\mathrm{V}_{\mathrm{dc}}\right)$ operates a significant role for controlling the reactive power $(\mathrm{Q})$ as clear in Fig. 8, where from starting to $(T=0.4 \mathrm{sec})$, the $\mathrm{V}_{\mathrm{dc}}$ is stable at the rated value $19.1 \mathrm{kV}$ because there is no change in reactive power. For a period bounded between $(0.4 \leq \mathrm{T} \leq 0.5) \mathrm{sec}$, the $\mathrm{V}_{\mathrm{dc}}$ decreased to $17.7 \mathrm{kV}$ in order to provide the system by the needed energy, finally for $(\mathrm{T}>0.5 \mathrm{sec}) \mathrm{V}_{\mathrm{dc}}$ increased to $20.7 \mathrm{kV}$ due to absorbing energy from the system. So, the $V_{d c}$ has an inversely relationship with needed reactive power.

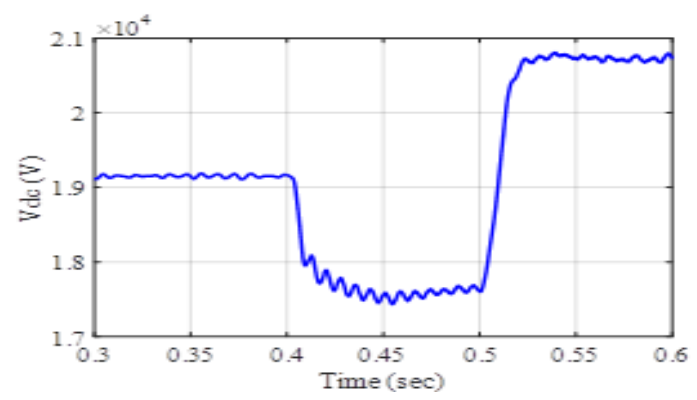

Fig. 8 DC capacitor voltage (STATCOM mode).

\subsection{SSSC Mode}

The SSSC used to control active power (P) transmitted by the transmission line. The active power is controlled and increased from 8.5 p.u to 9.5 p.u at 0.5 second as shown in Fig. 9.

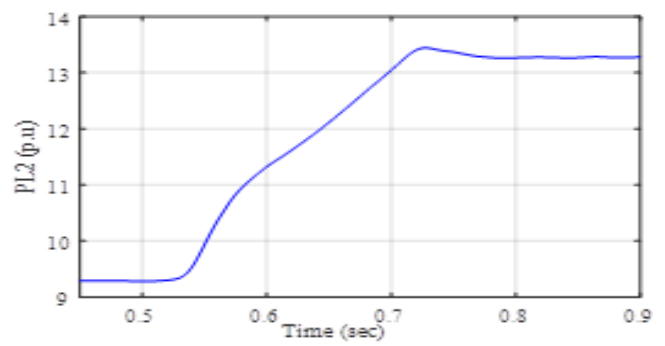

Fig. 9 Active power (P) of $\mathrm{L}_{2}$ vs Time (SSSC mode).

The adjustable injected voltage lead to control the active power of the second line, this injected voltage is shown in Fig. 10.

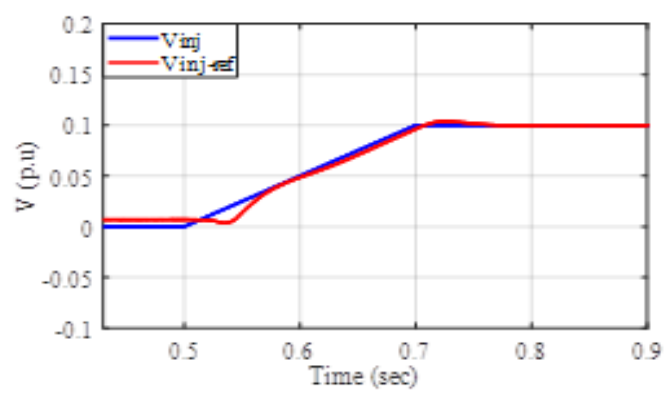

Fig. 10 Series injected voltage of $\mathrm{L}_{2}$ (SSSC mode).

As STATCOM case, the DC capacitor voltage $\left(\mathrm{V}_{\mathrm{dc}}\right)$ operates an important role for controlling the active power (P) as clear in Fig.11, where from starting to $(T=0.5 \mathrm{sec})$, the $V_{d c}$ is zero voltage because there is no change in reactive power, while for $(\mathrm{T}>0.5 \mathrm{sec})$ the steady state value of $\mathrm{V}_{\mathrm{dc}}$ increased to $18 \mathrm{kV}$. So, the $\mathrm{V}_{\mathrm{dc}}$ has a directly relationship with needed active power.

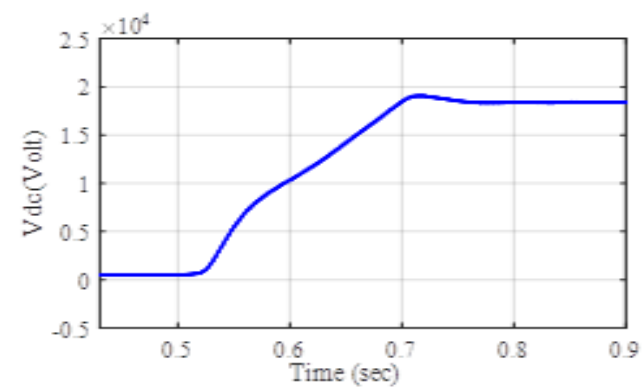

Fig. 11 DC Capacitor voltage (SSSC mode).

\subsection{UPFC Mode}


In this mode both active and reactive power have been controlled. The initial values of the real and reactive powers are $\left(\mathrm{P}_{\text {intial }}=8.5\right.$ p.u $)$ and $\left(Q_{\text {initial }}=-0.5\right.$ p.u $)$. At 0.25 second the active power is increased to 9.5 p.u as shown in Fig. 12.

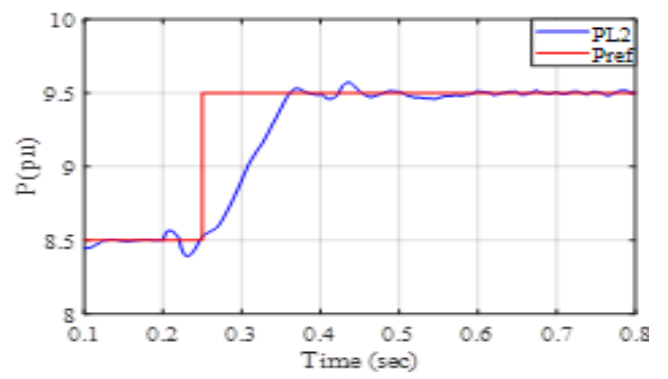

Fig. 12 Active power (P) of $\mathrm{L}_{2}$ vs Time(UPFC mode).

At 0.5 second the reactive power is increased to 0.5 p.u as shown in Fig. 13.

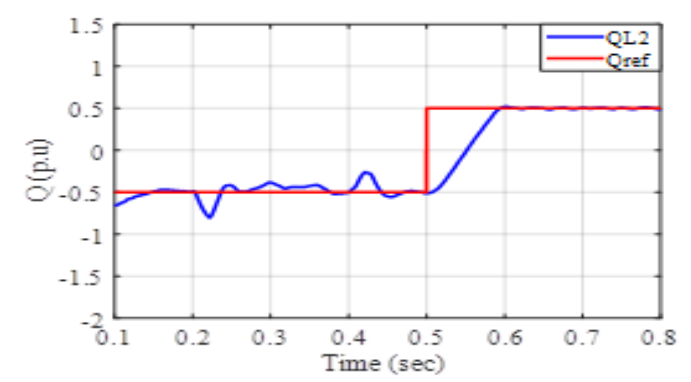

Fig. 13 Reactive power (Q) of $\mathrm{L}_{2}$ vs Time (UPFC mode).

From Fig. 11 and Fig. 12 it can conclude that the UPFC can realize the functions of both STATCOM and SSSC simultaneously. The DC capacitor voltage will be changed in order to control both active and reactive power as shown in Fig. 14.

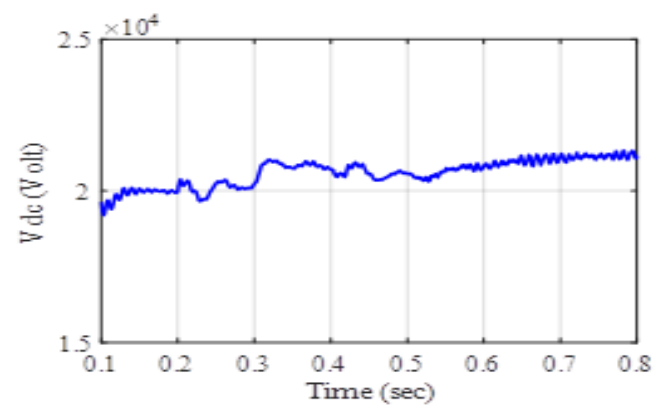

Fig. 14 DC Capacitor voltage (UPFC mode).

\subsection{Fast Fourier Transform (FFT) of the converter voltage}

As a result of using 48-pulse Multilevel Inverter (MLI), the line voltage will be nearly sinusoidal waveform with $(\mathrm{THD}=0.83 \%)$ as shown in Fig. 15.
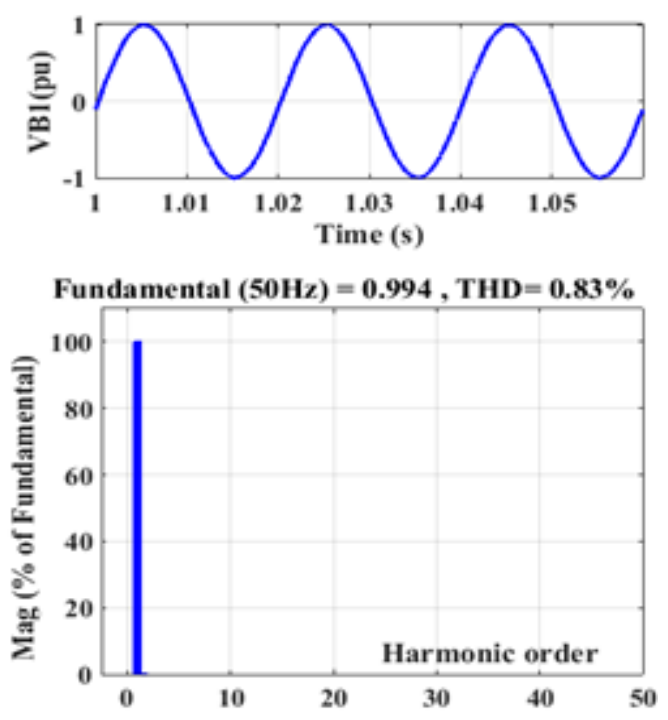

Fig.15 Total Harmonic Distortion (THD) of line $\left(\mathrm{L}_{2}=75 \mathrm{Km}\right)$.

\section{CONCLUSION}

FACTs are powerful technology to improve the power quality of the power system. In this paper a comparison study between three different types of FACTs devices is carried out and gives an idea about the FACTs devices. The main purpose of STATCOM is regulate line voltage by compensating the reactive power of the system. The STATCOM operates as an inductive load (absorbing reactive power). The SSSC controls the power of the transmission line by injecting regulating series voltage with phase shift $90^{\circ}$ with the line current. The UPFC is multifunction device that is collect the functions of STATCOM and SSSC together. by controlling both active and reactive power flow of the transmission line. The simulation results demonstrate the necessity of existent storage energy element like capacitor in the DC link side, as well as these results showed the effect of the DC link voltage into controlling an active and reactive power flow. The $\mathrm{V}_{\mathrm{dc}}$ has a reverse relationship with varying reactive power, while it has a direct relationship with varying active power, so it is very important to select a storage energy element with adjustable voltage at the DC link side in order to control both active and reactive power in efficient way. Both series and parallel converters are constructed by 48-pulse multilevel inverter, that decreased total harmonics distortion to $0.83 \%$. 


\section{REFERENCES}

[1] G. Shahgholian, E. Haghjoo, A. Seifi and I. Hassanzadeh, "The improvement DSTATCOM to enhance the quality of power using fuzzy 0 neural controller," Jour. of Trans. on Elec. Tech. (JTET), Vol.2, No.5, pp.3-17, 2010.

[2] S. Sankar and S. Ramareddy, "Digital simulation of closed loop controlled IPFC using PSPICE," International Journal of Electrical and Power Engineering, Vol.2, pp.99-103, 2008.

[3] K. M. Sze, L A .Snider, T. S. Chung and K. W. Chan, "Applications of PWM based static synchronous series compensator (SSSC) to enhance transient stability of power system," IEEE/APSCOM, pp.409-413, 2003.

[4] P. Kumkratug and P. Laohachai, "Direct Method of Transient Stability Assessment of a Power System with a SSSC," Journal of Computers, Vol. 2, No.8, pp. 77-82, 2007.

[5] A. Nimje, C. Panigrahi and A. Mohanty, "Enhanced Power Transfer Capability by using SSSC," Journal of Mechanical Engineering Research, Vol.3, No.2, pp. 48-56, 2011.

[6] L. Gyugyi, "Dynamic Compensation of AC Transmission Line by Solid State Synchronous Voltage Sources," IEEE Transactions on Power Delivery, Vol. 9, No.2, pp. 904-911, 1994.

[7] I. Musirin, N. Diamah, M. Radzi, M. Murtadha Othman, M. Khayatldris, and T. K. Abdul Rahman, "Voltage Profile Improvement using Unified Power Flow Controller via Artificial Immune System," WSEAS Transactions on Power Systems, Vol.3, No.4, pp. 194-204, 2008.

[8] P. Kumkratug and M.H. Haque, "Versatile Model of a Unified Power Flow Controller in Simple System," IEE Proc. Gener. Transm. \&Distrib., Vol.150. No.2, pp. 155-161, 2003.

[9] N. M. Tabatabaei, S. Abbasi, N. S. Boushehri and A. Jafari, "Overview Of STATCOM Technology," International Journal on Technical and Physical
Problems of Engineering (IJTPE), Vol. 7, No. 2, pp. 23-28, 2015.

[10] E. Kayar and H. F. Carlak, "Voltage Regulation Analysis in Energy Transmission Systems Using STATCOM," 2019 IEEE East-West Design \& Test Symposium (EWDTS), 13-16 Sept. 2019.

[11] S. Maturu and U. J. Shenoy, "Impact of STATCOM and SSSC Based Compensation on Transmission Line Protection," 16th National Power Systems Conference, 15th-17th December, 2010.

[12] A. Awad, S. Kamel, F. Jurado, H. M. Hasanien and A. Al-Durra, "A Simple Modeling of Static Series Synchronous Compensator in NEPLAN for Power System Control,"IECON 2019 - 45th Annual Conference of the IEEE Industrial Electronics Society, 14-17 Oct. 2019.

[13] S. Khanchi and V. Kumar Garg, "Unified Power Flow Controller (FACTS Device): A Review" International Journal of Engineering Research and Applications (IJERA), Vol. 3, No. 4, pp. 14301435, 2013.

[14] Qurratulain, E. Jamil, S. Hameed, "Mitigation of Power System Transients in a Multi-Machine System using Unified Power Flow Controller," $5^{T H}$ IEEE International Conference on Signal Processing, Computing and Control (ISPCC), 1012 Oct. 2019.

[15] R. Balam, K. Kalyani and B. Prasad, "Dynamic Performance of 48-pulse STATCOM, SSSC and UPFC controller", International Journal of Engineering Research and Applications (IJERA), Vol. 2, No. 1, pp.156-163, 2012.

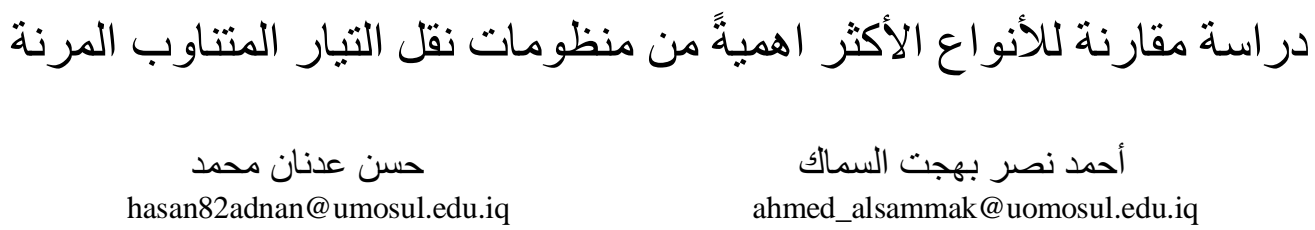

$$
\text { جامعة الموصل - كلية الهنسة - قسم الهندسة الكهربائية }
$$

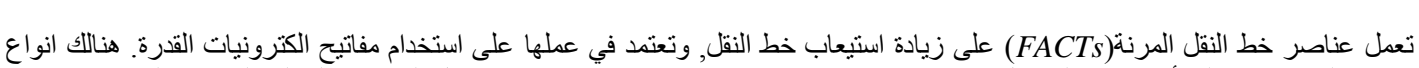

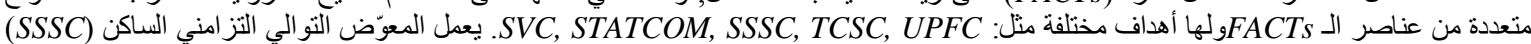

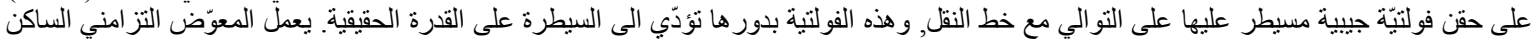
(STATCOM)

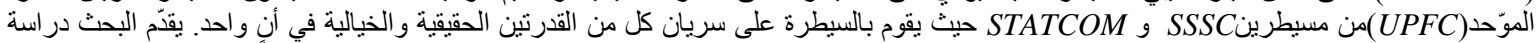

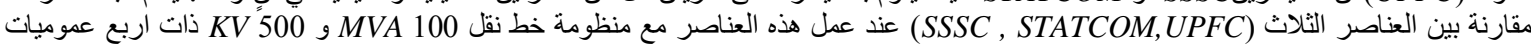

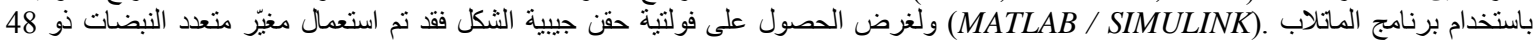

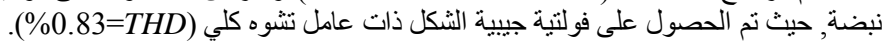

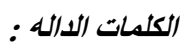

$$
\text { عناصر خط النقل المرنة، المعوض التو التي التز امني، المعوّض التزامني الساكن، مسيطر سريان القدرة الموحد الساكن،استقرارية الفولتية، نوعية }
$$

